\title{
Identification of cardiovascular risk factors among Hajj pilgrims from Bali 2018
}

\author{
N W Widhidewi*, S Masyeni and A Eka Pratiwi \\ Faculty of Medicine and Health Sciences, Universitas Warmadewa, Denpasar, Bali \\ *Corresponding author e-mail: wayanwidhidewi@gmail.com
}

\begin{abstract}
Almost 2 million Muslims from more than 183 countries conduct Hajj to Mecca, Saudi Arabia every year. This event carries significant public health challenges not only infectious disease transmission but also exacerbation of non-communicable diseases. Although the prevalence of cardiovascular disease (CVD) was not high, it confers high mortality rate. The aim of this study is to identify major risk factors of cardiovascular event among Hajj pilgrims from Bali in 2018. A cross sectional study was conducted in Western Denpasar Community Health Center, where the Hajj preparations take place. Demographical data, history of preexisting medical illness, physical examination, laboratory, electrocardiogram (ECG) and thorax x-ray results were collected. CVD risk defined as the finding of at least one of the parameters (hypertension, diabetes mellitus, dyslipidemia, hyperuricemia, ECG or X-ray abnormalities). A total of 99 participants were enrolled in the study. Among them, 97 (98\%) participants had at least one CVD risk factor. Significant findings of Hajj Pilgrimage with CVD risk implicate that the CVD risk factors identification are profoundly recommended to prevent mortality and morbidity related to cardiovascular event during Hajj-period.
\end{abstract}

\section{Introduction}

Almost 2 million Muslims from more than 183 countries conduct Hajj to Mecca, Saudi Arabia every year [1]. Hajj is the major religious ritual for every Muslim who has been stable in terms of physic, psychology and finance, at least once in their lifetime. This event carries significant public health challenges not only infectious disease transmission but also exacerbation of non-infectious disease or non-communicable diseases. The diseases pattern among Hajj Pilgrims attending Medical facilities of Pakistani was respiratory disease, musculoskeletal disorder, gastrointestinal disease, ear nose throat disease, skin disease, cardiovascular disease and others, which frequencies were $29 \%, 18 \%, 15 \%, 8 \%$, $6 \%$ and $2 \%$, respectively [2]. Although the prevalence of cardiovascular disease was not high, it confers high mortality rate reported by the other study [3].

Cardiovascular disease (CVD) including coronary heart disease (CHD), stroke and heart failure are the leading cause of morbidity and mortality during Hajj [4,5]. The mortality rate of CVD with hypertension during hajj was reported as high as $45.8 \%$, meanwhile cerebrovascular disease mortality rate was 3.4\% [6]. Another study also supports that non-communicable diseases, mainly cardiovascular events, are the major causes of morbidity and mortality among young and elderly pilgrims with pre-existing illnesses [7]. The CVD has been reported as the cause of $64 \%$ admission to intensive care unit [8]. The outcome of the CVD among Hajj pilgrims admitted in All-Nurr Hospital, Makkah was discharged with stable condition (84\%), discharged against medical advice (9\%), unable to perform Hajj (4.5\%) and died as high as 2.5\% [9]. The median age of French pilgrim was 61 years old, while pilgrim's ages ranging from 65 to 74 years old had high number of age-related chronic illness such as diabetes mellitus (21\%) and hypertension (21\%) [10].

Hajj ritual consists of several activities which require significant amount of optimal physical exertion. Walking around the Kaaba, a cube-shaped building in Mecca considered as the most sacred site in Moslem, which is followed by walking between two hills (Safa and Marwa) for about $3.15 \mathrm{~km}$ in distance is not only the activity of the Hajj. Another exhausting activity is the $14.5 \mathrm{~km}$ journey to 
Arafat desert which is followed by the day in when the Hajj should spend a night at Muzdalifah to throw the gravels at Mena (Mulyana and Gunawan). Hence, the performance of the people joining Hajj pilgrimage should be in a good health and can afford to take the journey. Screening for several chronic illnesses for the Hajj joining the pilgrimage is obligatory and must be conducted in one or two months prior to the journey. Heart failure, serious arrhythmia, uncontrolled hypertension, unstable angina, recent cardio and cerebrovascular diseases and other illnesses which are unfit for fly are also considered to unfit to undertaking the Hajj pilgrimage [11].

Indonesia contributes as high as $10 \%$ of the pilgrimage before 2008 , with the mortality rate for the Indonesian pilgrims ranging from 200 to 380 deaths per 100.000 pilgrims during 10-weeks Hajj periods [12]. According to this study, in 2008, among 206,831 Indonesian pilgrims, there were 446 deaths found (equivalent to 1,968 deaths per 100.000 pilgrim's years). The highest of the death factors were related to CVD (66\%) followed by respiratory disease (28\%). The high mortality rate among Indonesian pilgrims occurs despite the pre-departure health screening having been done. Therefore, more extensive identifications of cardio cerebrovascular risk factors among the pre-Hajj pilgrims are profoundly recommended.

The aim of this study is to identify major risk factors of cardiovascular event among Hajj pilgrims from Denpasar Bali in 2018.

\section{Methods}

\subsection{Data Collection}

A cross sectional study was conducted with a total of 99 participants. Participants were screened and recruited in Western Denpasar Community Health Centers, where the Hajj preparations take place. Pilgrims older than 18 years old were included after signing the informed consent. Demographic data include age, gender and date of birth. History of cigarette smoking and alcohol consumption were obtained from the participants. Result of physical examination, laboratory testing, electrocardiography and radiography were also collected. Body Mass Index (BMI) was calculated as weight in kilograms divided by the square of height in meters using Microsoft Office Excel 2010.

Their past medical history or the preexisting illness were obtained from the participants; included history of cardiac diseases, diabetes mellitus, hypertension, dyslipidemia, chronic kidney disease, chronic liver disease, chronic respiratory disease, chronic diarrhea and stroke. Five ml fasting blood samples were taken to be tested for complete blood count, kidney function test, liver function test, blood sugar level, lipid profile and uric acid level. Electrocardiography was done by professional nurse. The participants also undergo chest $\mathrm{x}$-ray in the radiologic center (for participants older than 40 years old)

\subsection{Statistical Analysis}

Pearson's Chi-square or Fisher's exact tests were used to compare univariate categorical data. All statistical analyses were performed using SPSS 23.0. The results were expressed in terms of number and percentage.

CVD risk was defined as the finding of at least one of the variables: cigarette smoking, alcohol consumption, obesity, hypertension, diabetes mellitus, dyslipidemia, hyperuricemia, ECG or x-ray abnormalities).

\subsection{Ethical Consideration}

The study, the collection of clinical and epidemiological data was submitted for ethical approval to the Research Ethic Committee of Universitas Udayana, Denpasar. Enrolment of the study participants is conditional on appropriate consent. 


\section{Result}

From one public health center in Western Denpasar, 99 Hajj Pilgrim were enrolled to this study. Most of the Hajj Pilgrim aged 41-50 years old, with more than a half of them was female (table 1).

Table 1. Demographic characteristics of participants

\begin{tabular}{clc}
\hline Variable & \multicolumn{1}{c}{ Description } & N (\%) \\
\hline \multirow{4}{*}{ Age } & $18-30$ years old & $3(3.1)$ \\
& $31-40$ years old & $10(10.1)$ \\
& $41-50$ years old & $34(34.4)$ \\
& $51-60$ years old & $25(25.3)$ \\
Gender & $>60$ years old & $8(8.1)$ \\
& Male & $42(42.4)$ \\
& Female & $57(57.6)$ \\
\hline
\end{tabular}

Table 2 showed that the main chronic diseases history in Hajj Pilgrim from Bali was hypertension (26.3\%), diabetes mellitus (15.2\%) and chronic lung disease (7.1\%). Ten percent of the Hajj had history of cigarette smoking (table 2). The most common current illness as cardiovascular risk factor in Hajj Pilgrim from Denpasar was dyslipidemia (77.8\%), followed by obesity $(62.7 \%)$ and hypertension $(37.4 \%)$

Table 2. Cardiovascular risk factors of Hajj pilgrims

\begin{tabular}{clc}
\hline \multicolumn{1}{c}{ Variable } & \multicolumn{1}{c}{ Description } & N (\%) \\
\hline & Hypertension & $26(26.3)$ \\
& Diabetes mellitus & $15(15.2)$ \\
& Chronic lung disease & $7(7.1)$ \\
Past medical history & Cardiac disease & $2(2.1)$ \\
& Dyslipidemia & $1(1.0)$ \\
& Stroke & $1(1.0)$ \\
& Chronic kidney disease & $0(0.0)$ \\
Social history & Chronic liver disease & $0(0.0)$ \\
& Cigarette smoking & $10(10.1)$ \\
& Alcohol consumption & $1(1)$ \\
& Dyslipidemia & $77(77.8)$ \\
& Obesity & $62(62.7)$ \\
Current illness & Hypertension & $37(37.4)$ \\
& X-ray abnormalities & $36(36.4)$ \\
& ECG abnormalities & $32(32.3)$ \\
& Hyperglycemia & $19(19.2)$ \\
& Hyperuricemia & $15(15.2)$ \\
\hline
\end{tabular}

Figure 1 showed the percentage of Hajj Pilgrim that had at least one risk factor based on their current illness, past medical history and social history. The total number of Hajj Pilgrims that were at risk of having cardiovascular event was 97 persons (98\%). 


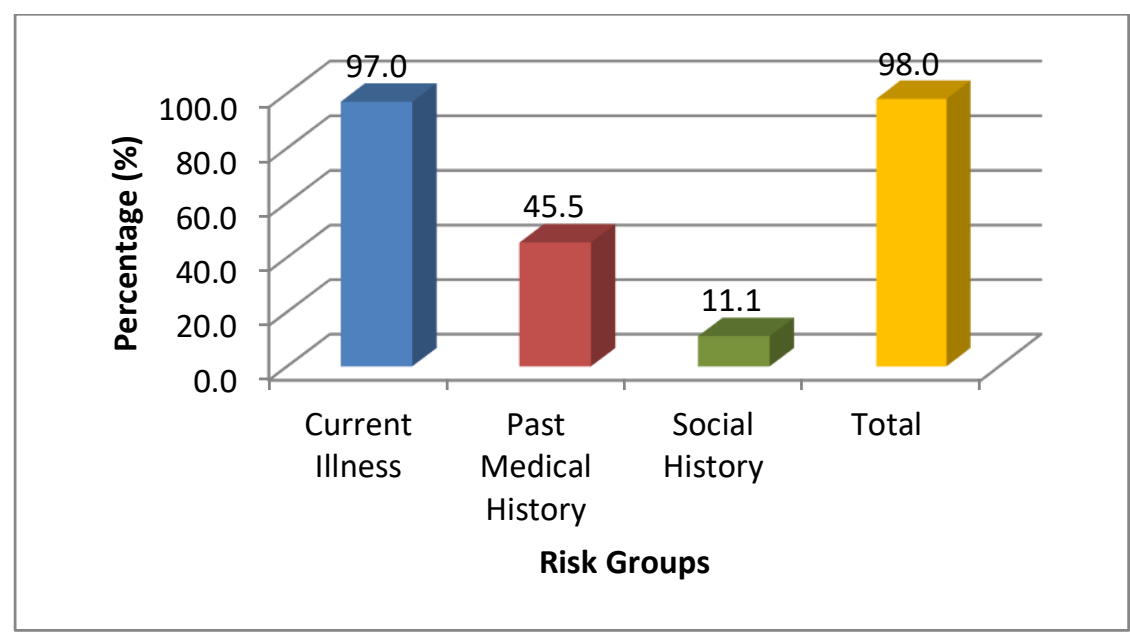

Figure 1. Percentage of Hajj pilgrim with cardiovascular risk factors

\section{Discussion}

Over the past few years, cardiovascular diseases have emerged as an important cause both of intensive care unit (ICU) admission and of mortality during Hajj. More than $60 \%$ of patients admitted to ICU caused by myocardial infarction and failure of left ventricle (Al Shimemeri, 2012). The most common current illnesses of Denpasar pilgrims in 2018 as the risk factor of CVD were dyslipidemia and obesity, with more than $50 \%$ prevalence each.

The main past medical history of the pilgrims that increased the risk of having cardiovascular event were hypertension and diabetes mellitus with the percentage of $26.3 \%$ and $15.2 \%$, respectively. This result was in accordance with a study involved 379 Malaysian Pilgrims in 2013 which stated that the most common health problem before pilgrimage were hypertension $(48.3 \%)$ and diabetes $(25.2 \%)$. That study also obtained health problems during Pilgrimage among Malaysian pilgrims. They discovered that the main problem was respiratory diseases $(77.5 \%)$, followed by fever $(15.0 \%)$ [13].

The limitations of our study were the total number of samples that are relatively small for a survey and we did not obtain data about diseases experienced by the Pilgrims during Pilgrimage. The next study should involve more health care centers and participants to discover more reliable results. Also it is important to gather data after Pilgrimage to explore the incidence of cardiovascular event during Pilgrimage, also their morbidity and mortality rate. The proportion of Hajj Pilgrim having cardiovascular risk factors that actually suffer from cardiovascular diseases during Pilgrimage can also be calculated.

\section{Conclusion}

Significant findings of Hajj Pilgrims with CVD risk implicate that the CVD risk factors identification are profoundly recommended to prevent mortality and morbidity related to cardiovascular event during Hajj-period. A health education and precautionary measure can be shared to the Hajj pilgrims with cardiovascular risk factors to prevent the risks to become an illness during Pilgrimage.

\section{References}

[1] Shafi S, Dar O, Khan M, Azhar E I, McCloskey B, Zumla A. and Petersen E 2016 The annual hajj pilgrimage - minimizing the risk of ill health in pilgrims from europe and opportunity for driving the best prevention and health promotion guidelines International Journal of Infectious Diseases $\mathbf{4 7}$ pp 79-82

[2] Raja W, Aziz A, Hassan T B, Jalil M, Niazi I U, Jawaid N and Tariq M 2017 Disease patterns among hajj pilgrims attending medical facilities of pakistan hajj medical mission 2016 (1437 hijri) Pakistan Armed Forces Medical Journal 67 
[3] Aljoudi A S 2013 A university of the hajj? The Lancet 382 p 1689

[4] Al Shimameri A 2012 Cardiovascular disease in hajj pilgrims Journal of the Saudi Heart Association 24 pp 123-7

[5] Al Masud S M R, Bakar A A and Yussof S 2016 Determining the types of diseases and emergency issues in pilgrims during hajj: a literature review Statistics and Information $5 \mathrm{p} 7$

[6] Arabi Y M and Alhamid S M 2006 Emergency room to the intensive care unit in hajj the chain of life. Saudi Medical Journal 27 pp 937-41

[7] Memish Z A, Zumla A, Alhakeem R F, Assiri A, Turkestani A, Al Harby K D, Alyemni M, Dhafar K, Gautret P and Barbeschi M 2014 Hajj: infectious disease surveillance and control The Lancet $\mathbf{3 8 3}$ pp 2073-82

[8] Madani T 2007 Causes of admission to intensive care units in the hajj period of the islamic year 1424 (2004) Ann. Saudi. Med. 27

[9] Serafi A S 2010 Pattern of cardiovascular diseases in pilgrims admitted in al-noor hospital makkah during hajj 1429h Pak. J. Physiol. 6

[10] Gautret P, Soula G, Delmont J, Parola P and Brouqui P 2009 Common health hazards in french pilgrims during the hajj of 2007: a prospective cohort study Journal of Travel Medicine 16 pp 377-81

[11] Chamsi-Pasha H, Ahmed W H and Al-Shaibi K F 2014 The cardiac patient during ramadan and hajj Journal of the Saudi Heart Association 26 pp 212-5

[12] Pane M, Imari S, Alwi Q, Kandun I N, Cook A R and Samaan G. 2013. Causes of mortality for indonesian hajj pilgrims: comparison between routine death certificate and verbal autopsy findings Plos One 8 e73243

[13] Nor Radhiah M N, Rosminah M, Suhaimi A W and Omar O 2017 The fundamental of hajj demand for health care services within congestion in Makkah Malaysian Journal of Public Health Medicine 17 pp 84-93 